\title{
AMBIENTALIZAÇÃO E POLITIZAÇÃO DO CONSUMO NAS PRÁTICAS DE COMPRA DE ORGÂNICOS
}

\author{
Marcelo Castañeda*
}

\begin{abstract}
O objetivo é refletir sobre processos de ambientalização e politização do consumo e do cotidiano, enfatizando o multifacetado campo da alimentação. $O$ artigo se volta para os diferentes usos das práticas de compra de alimentos orgânicos, entendendo os consumidores como atores sociais. A problemática central encontra-se nas seguintes questões: as práticas de compra de alimentos orgânicos são percebidas como forma de ação política? De que forma os consumidores lidam com os discursos e cobranças de responsabilidades pela crise ambiental? Com uma etnografia das práticas de compra de alimentos orgânicos e entrevistas em profundidade, o artigo identifica um aumento da autonomia política individual no encontro das esferas pública e privada no campo do consumo. A compra de orgânicos é percebida como um repertório de ação política romântico-individualista, sendo que essas práticas alimentam pontes com a cidadania, abrindo possibilidades para novos engajamentos coletivos.

PALAVRAS-CHAVE: ambientalização e politização do consumo, cotidiano, práticas de compra, alimentação orgânica.
\end{abstract}

\section{INTRODUÇÃO}

A politização da esfera do consumo se refere à percepção e ao uso das práticas e escolhas de consumo como uma forma de participação na esfera pública nas sociedades contemporâneas. ${ }^{1}$ Trata-se de um processo que apresenta estreita relação com a ambientalização da vida cotidiana, percebida com mais intensidade a partir dos anos 1990. Ambos os processos tratam da tentativa de dar concretude à adesão dos agentes consumidores a valores em prol de melhorias sociais e ambientais, materializando-os e tornando-os públicos (Portilho, 2005; Stolle et al, 2005).

Com isso, as ações e escolhas mais triviais e cotidianas passam a ser percebidas como capa-

* Doutorando em Ciências Sociais em Desenvolvimento, Agricultura e Sociedade pela Universidade Federal Rural do Rio de Janeiro (CPDA/UFRRJ). celocastaneda@gmail.com

${ }^{1} \mathrm{O}$ uso das práticas de consumo como forma de "participação na esfera pública" e "ação política" constitui questão emergente para a investigação das ciências sociais contemporâneas. Essas questões se somam aos temas recorrentemente pesquisados nos Estudos do Consumo, como destacado por Portilho (2008): a reprodução material e simbólica, a construção, fortalecimento e marcação de identidades, a distinção social, a comunicação, o pertencimento, a cidadania e a sociabilidade. zes de influenciar os rumos globais, ao mesmo tempo em que se tornam globalmente influenciadas (Giddens, 1997). Ações como boicotes e buycotts $^{2}$ (Stolle et al, 2005), além das diversas formas de racionalização no uso doméstico de bens e serviços, como água, energia, automóvel, separação de resíduos, entre outros (Portilho; Castañeda, 2009), destacam-se como práticas politizadas, em um contexto neomoderno ${ }^{3}$ (Alexander, 1995).

O uso político do consumo não constitui uma novidade, mas essas táticas tornam-se específicas e predominantes nas sociedades con-

${ }^{2} \mathrm{O}$ neologismo buycott tem sido utilizado na língua inglesa como contraponto à noção de boycott. Enquanto esse último refere-se à negação da compra como forma de protesto, uma ação de buycott refere-se à opção consciente de compra de produtos e serviços percebidos como social e ambientalmente responsáveis (Portilho; Castañeda, 2009).

${ }^{3}$ A perspectiva neomoderna de Alexander (1995) traz como ponto de referência empírico comum um código familiar de cidadão/sagrado e inimigo/profano, que permite à história ser narrada de maneira teleológica, fortalecendo o drama da democracia. $\mathrm{O}$ autor permite entender uma possível transição no padrão de ação política nas sociedades contemporâneas, caracterizada, de um lado, por uma relativa deflacão das ações "radicais-coletivistas", hegemônicas no período antimodernização dos anos 1960 e 1970 e, de outro, pela emergência de ações "românticoindividualístas", que parecem predominar atualmente. 
temporâneas: são mais individuais do que coletivas (Stolle et al, 2005); refletem a defesa e escolha de um modo de vida (Portilho, 2005; Portilho; Castañeda, 2009); e podem remeter a uma reinvenção da política, de seus temas e atores e do próprio campo político (Alexander, 1995; Giddens, 1996; Beck, 1997; Portilho, 2009).

Nainterface entre consumo esustentabilidade, ações políticas romântico-individualistas (Alexander, 1995) podem ser interpretadas como parte dos processos de ambientalização e politização do consumo e da vida privada e cotidiana em curso nas sociedades contemporâneas. Nesse sentido, uma autoatribuição de responsabilidades individuais (Eden, 1993) é reforçada e fortalecida por estímulos e cobranças dos mercados, Estados, organizações não governamentais, opinião pública e mídia, para os indivíduos considerarem variáveis ambientais em suas preocupações e experiências cotidianas, negociando, ética e politicamente, suas escolhas e ações (Portilho, 2005).

Portilho (2005) compreende esse movimento como uma possibilidade de fortalecer a participação política na esfera pública, nas sociedades contemporâneas, gerando uma ética da responsabilidade reflexiva, capaz de romper com as rotinas silenciosas, ${ }^{4}$ ao difundir novos valores e comportamentos nas redes sociais de uma esfera micropública, onde as demandas e as ações são discutidas e negociadas. As experiências coletivas podem ser construídas em torno dos dilemas e conflitos relacionados às políticas ambientais. $\mathrm{O}$ desafio passa a ser, então, a comunicação de mensagens entre essas microesferas privadas e uma esfera pública mais ampla.

Em pesquisa recente, Castañeda de Arau-

${ }^{4} \mathrm{O}$ cenário mais limitado também é vislumbrado por Portilho (2005) no caso de os consumidores experimentarem considerações ambientais em seu cotidiano de forma "silenciosa" e individual. Ao não discutir esse assunto em seus grupos ou redes sociais, esse movimento pode reforçar a redução da esfera pública bem como a dependência dos consumidores em relação aos produtores (Paavola, 2001). Com isso, a estratégia de um consumidor individual como principal ator para resolver os problemas ambientais pode gerar uma perda do sentimento de comunidade e coletividade, além de fazer com que os consumidores dependam de lógicas institucionais, como, por exemplo, o conhecimento dos especialistas e dos mecanismos de mercado (Halkier, 1999 apud Portilho, 2005) jo (2010) compreende o desempenho em práticas de compra de alimentos orgânicos como uma das possíveis materializações dos processos de ambientalização e politização do consumo e da vida cotidiana. O autor relaciona as práticas de compra desses alimentos com as dimensões éticas e políticas da alimentação em um contexto de crise ambiental, em uma sociedade de risco global. ${ }^{5}$ Essas práticas parecem ampliar o campo político em direção à esfera privada e à vida cotidiana, em uma sociedade reflexiva, configurando subpolíticas (Beck, 2002) ou políticas de vida (Giddens, 1996).

Nas sociedades contemporâneas, a posição dos alimentos orgânicos - vista a partir da construção de um campo dialógico multidimensional sobre os problemas socioambientais e a questão da sustentabilidade planetária-envolve dimensões por vezes conflituosas, tais como o mercado, o movimento social de agricultura alternativa, a certificação e o imaginário dos consumidores. Atualmente, esses alimentos estão inseridos no mainstreaming mercadológico, em função da intensa e crescente comercialização pela via dos supermercados e da absorção de padrões agroindustriais, aspectos que são objeto de uma crítica agroecológica mais radical.

Apesar disso, o movimento social de agroecologia mantém um dinamismo que pode ser verificado pela manutenção de espaços de comercialização, como as feiras orgânicas, certificadas ou não, e os canais de venda direta, apesar da, cada vez mais evidente, hegemonia dos supermercados, especialmente nos grandes centros.

Assim, o presente artigo foi configurado como desdobramento de um trabalho de campo etnográfico ${ }^{6}$ que envolveu observação participan-

\footnotetext{
5 Atualmente, os hábitos alimentares incorporam elementos que permitem uma abordagem política, ideológica e ética, transcendendo os aspectos nutricionais, simbólicos, sociais e históricos associados à alimentação (Barbosa, 2009) Por outro lado, cada vez mais, as ansiedades dos consumidores em relação à confiança e aos riscos presentes nos alimentos, por exemplo, transcendem a esfera privada, apresentando reflexos diretos na esfera pública (Lien, 2004).

${ }^{6} \mathrm{O}$ trabalho de campo em questão foi desenvolvido como parte da pesquisa que resultou na dissertação de mestrado "Ambientalização e politização do consumo e da vida cotidiana: uma etnografia das práticas de compra de alimen-
} 
te junto aos consumidores de alimentos orgânicos em Nova Friburgo (RJ), no ato da compra desses alimentos em supermercados, feiras, estabelecimentos especializados em hortifruti, lojas de produtos artesanais e naturais, padarias, delicatessens e lojas de conveniência. Também foram realizadas 15 entrevistas em profundidade. ${ }^{7}$

Como na etnografia de Miller (2002), que é base da sua teoria das compras como rituais de sacrifício, as práticas de compra de alimentos orgânicos configuravam um elemento inerente ao abastecimento rotineiro dos lares de consumidores observados em Nova Friburgo (RJ), o que se confirma pela frequência semanal do desempenho de compra.

Cabe destacar que a compra não pode ser compreendida como um ato individualista ou individualizante. Warde (2005) e Miller (2002) mostram que o ato de compra não se relaciona apenas com a subjetividade, além de raramente ser dirigido pela individualidade do consumidor que pratica a compra. Com isso, as práticas de compra de alimentos orgânicos podem ser interpretadas como rituais contemporâneos, considerando as duas formas de alteridade relacionadas com a compra de mercadorias para o abastecimento rotineiro do lar:

A primeira delas expressa uma relação entre o comprador e outro indivíduo particular como criança ou parceiro, podendo estar presente no domicílio, ser desejado ou imaginado. A segunda é uma relação com um objetivo mais geral que transcende qualquer utilidade imediata e é mais bem compreendida como cosmológica à medida que assume forma não de sujeito ou de objeto, mas dos valores aos quais as pessoas desejariam se dedicar (Miller, 2002, p. 27).

tos orgânicos em Nova Friburgo/RJ”, defendida por Castañeda de Araujo (2010) no CPDA/UFRRJ. Uma primeira etapa foi desenvolvida entre dezembro de 2008 e janeiro de 2009, compreendendo visitas aos locais de aquisição de produtos orgânicos, procurando interagir com esses atores. Uma segunda etapa foi empreendida entre julho e outubro de 2009, com visitas aos locais de aquisição, com ênfase na observação das práticas de compra de alimentos orgânicos. Foram realizadas 26 visitas aos locais de aquisição, com aproximadamente 80 interações com consumidores.

${ }^{7}$ As entrevistas em profundidade foram interpretadas por meio de uma matriz de análise de conteúdo categorial (Bardin, 1977).
Apesar do desempenho individualizado dos consumidores na compra, ela não é praticada de forma isolada, como pressupõe a abordagem da economia neoclássica, pois se volta para outras pessoas do círculo de relações pessoais desses consumidores. Cosmologicamente, a compra também é dirigida pela possibilidade de contribuir com a preservação do meio ambiente e a "melhoria do planeta" e - com menos intensidade - da vida dos produtores rurais. Essa dupla alteridade caracteriza as práticas de compra de alimentos orgânicos e marca, de forma crucial, o desenvolvimento dos processos de ambientalização e politização no contexto pesquisado.

A análise de Warde (2005) sobre as teorias das práticas torna-se central ao assinalar duas noções centrais ao conceito de práticas. A primeira é a noção de prática como uma entidade coordenada, que compreende os nexos ${ }^{8}$ de fazeres e de discursos desdobrados no tempo e dispersos no espaço. A outra é a de desempenho, que envolve os diferentes modos de compreender uma multiplicidade de ações simples e constantes que se reproduzem nas práticas. Nesse sentido, o indivíduo pode ser entendido como um agente corporal e mental que segue práticas muito diferentes sem que apresentem, necessariamente, coordenação entre si.

Dessa forma, as práticas são formas sociais rotinizadas, que tornam possível compreender o movimento dos corpos, o manuseio dos objetos, o tratamento dos sujeitos, a descrição das coisas e o entendimento do mundo. O consumo, assim, pode ser entendido como um fenômeno social multidimensional que se manifesta como conjunto de práticas, cuja natureza e cujos processos podem ser compreendidos pela participação individual em práticas que podem assumir diferentes significados.

Na sequência do artigo, destaco a especificidade política do campo da alimentação nas

${ }^{8}$ Warde (2005) entende que os nexos se conectam por meio de três elementos: os entendimentos sobre o que dizer e fazer; os procedimentos explicitados por meio de regras, princípios, preceitos e instruções; e os engajamentos em estruturas teleológico-afetivas que compreendem fins, projetos, questões, propósitos, crenças, emoções e ânimos. 
sociedades contemporâneas a fim de caracterizar a autoatribuição de responsabilidades e as formas de ação política adotadas pelos consumidores de alimentos orgânicos.

\section{A ESPECIFICIDADE POLÍTICA DAALIMENTA- ÇÃO NAS SOCIEDADES CONTEMPORÂNEAS}

Em um passado não muito distante, uma abordagem política da alimentação teria um lugar restrito à atuação da burocracia estatal em questões como segurança alimentar, desigualdade social e política nutricional e agrícola. Até meados dos anos 1980, o foco se voltaria, no máximo, para o acesso à comida em diferentes níveis, considerando preferencial e fundamentalmente os aspectos nutricionais. As políticas se limitariam, assim, ao "fazer" institucional.

No entanto, nas últimas décadas, o campo da alimentação adquiriu importância e visibilidade como lazer e experiência multissensorial, mas também como ato político e ideológico (Barbosa, 2009), indo além de práticas relacionadas com a satisfação de necessidades individuais vitais, modeladas pela cultura e imprescindíveis para a vida e a sobrevivência humanas (Canesqui; Garcia, 2005).

Barbosa (2009) assinala uma transição do ato de comer como a passagem de uma atividade corriqueira, prazerosa, privada e familiar para uma prática altamente consciente, regulada e política. Nesse sentido, indica as origens da complexidade atual no campo da alimentação em múltiplas esferas, tais como: o conhecimento científico sobre a nutrição humana e a medicina; o movimento ecológico, que pauta as implicações ambientais decorrentes do tipo de consumo alimentar que as sociedades ocidentais contemporâneas adotaram; os movimentos sociais em defesa de populações que vivem de métodos tradicionais de produção, e encontram-se ameaçadas pelas transformações ocorridas no campo; os movimentos em defesa dos animais; o processo de globalização; e o desenvolvimento das ciências sociais no sentido de abordar os fenômenos de forma mais processual e relacional, analisando as redes ao invés de individualizá-los analiticamente.

Com isso, cada garfada parece aglutinar experiências locais, particulares e subjetivas do ato de comer a eventos que ocorrem no cenário global. Esse novo papel da alimentação nas sociedades contemporâneas se relaciona fundamentalmente com a consciência das questões que envolvem o que comemos; as responsabilidades derivadas dessa consciência; as implicações da globalização; e o teor político e ideológico dessas questões.

A capacidade de efetuar conexões confere especificidade política às práticas alimentares nas sociedades contemporâneas. Essas conexões marcam politicamente o campo da alimentação, indicando possibilidades de "dissolver muitas distinções preconcebidas entre natureza e cultura, produção e consumo, moral e mercado, família e sociedade, individual e coletivo, corpo e mente" (Lien, 2004, p.9).

O campo da alimentação se torna político na medida em que muitas relações de poder se constituem nele, bem como por meio dele. Configura-se, assim, um campo de disputas específicas que conectam o corpo individual a comunidades abstratas e inovações técnico-científicas de conceitos morais, evidenciando dilemas acerca dos riscos e do controle que caracterizam a produção de alimentos nas sociedades contemporâneas.

Durante os anos 1990, Lien (2004) assinala um transbordamento da política no campo da alimentação. A esfera da vida cotidiana passa a incorporar um sentido político a partir do momento em que questões como controvérsia, hegemonia, resistência e conflitos de interesse passaram a permear as escolhas alimentares dos consumidores. Os indivíduos começaram a desenvolver uma percepção em relação à comida, associada à desconfiança nas instituições políticas, especialmente com a emergência da noção de risco em decorrência de seguidas epidemias e 
escândalos alimentares, ${ }^{9}$ além da introdução dos alimentos transgênicos na pauta de discussões públicas. $^{10}$

Os anos 1990 representaram uma virada histórica na configuração da alimentação como campo político. O alimento deixou de ser apenas um recurso material que supre a necessidade básica de sobrevivência, ou um importante elemento cultural, incorporando a necessidade de equilíbrio entre os gastos monetários e os riscos e desconfianças dos consumidores. O alimento e a comida se tornaram politizados tanto como mercadoria para consumo quanto pelo crescente interesse em sua rastreabilidade. ${ }^{11}$

Uma abordagem política do campo da alimentação implica, portanto, discutir a noção de alimento e o seu "dever-ser", indo além das políticas públicas dos Estados-nação, para se conectar a inovações e discursos de arenas transnacionais da ciência, da tecnologia e do mercado. Além do acesso e da produção dos alimentos, certos engajamentos políticos e morais distanciados como, por exemplo, aqueles desempenhados em boicotes, petições on-line e ações do ativismo ambiental global evidenciam o teor político nesse campo.

Lien (2004) compreende, assim, um movimento duplo de mudança, que envolve um desencaixe local e um reencaixe global,,$^{12} \mathrm{com}$

${ }^{9}$ Entre as epidemias e os escândalos alimentares, Lien (2004) relaciona o "mal da vaca louca", a febre aftosa e a questão da salmonela no frango. Mais recentemente, a epidemia de "gripe suína" vem reforçar esse sentido, bem como, por exemplo, no Brasil a descoberta recente de soda caústica no leite.

${ }^{10}$ Entretanto, apesar dos debates recentes sobre transgênicos, o trabalho de campo que realizei em Nova Friburgo (RJ) aponta a presença de agrotóxicos nos alimentos como a preocupação mais candente entre os consumidores de alimentos orgânicos brasileiros.

${ }^{11}$ Lien (2004) entende a rastreabilidade como a trajetória do alimento: desde o modo de produção até a cozinha e o momento das refeições, com implicações no preparo da comida e no cuidado com a família.

${ }^{12}$ Nas últimas décadas, em decorrência da globalização da comida e dos sistemas nutricionais, Lien (2004) compreende que as grandes distâncias percorridas pelos alimentos provocaram uma deslocalização, entendida como reflexo do crescimento em extensão das redes globais, da intensidade e do impacto das interconexões globais, bem como da velocidade dos fluxos globais. Nesse caso, interpretei o termo deslocalização como um dos desencaixes da modernidade, que teve seu consequente reencaixe na alta modernidade, nos termos da análise efetuada por Giddens (1991). um impacto cada vez maior de eventos locais em contextos distantes de uma ordem globalizada. Assim, certos consumidores passam a se autoatribuir responsabilidades (Eden, 1993) frente a relações distantes, complexas e abstratas, inserindo a vida cotidiana no campo político. Por outro lado, os consumidores globais ficam vulneráveis às práticas, regulações e rotinas originadas em regiões distantes e desconhecidas. Com isso, as negligências, fraudes e adulterações do complexo agroalimentar industrial hegemônico passam a representar riscos para todos os consumidores de alimentos.

No entanto, não é só o fato de a comida se tornar globalizada que faz da alimentação um campo político, nem mesmo a ampliação dos interesses, relações e instrumentos regulatórios envolvidos na trajetória do alimento, da produção ao consumo. Um potencial maior de interesses divergentes e conflitantes torna as relações políticas do alimento e da comida faz com que cada alimento passe a ser reconhecido como um produto que possui uma história e implicações mais complexas e profundas do que se pensara até então.

Lien (2004) entende que a distância entre o que sabemos e o que poderíamos saber confere à segurança e à transparência um caráter fundamental nas análises sobre a alimentação contemporânea. Uma abordagem política do campo da alimentação é, ao mesmo tempo, silenciosa e expositiva, na medida em que envolve o poder de controlar o que será declarado e a definição do foco de debate público, assim como o que deixará de ser declarado.

As relações abstratas entre produtores e consumidores, o enfraquecimento da autoridade especialista e a divulgação frequente dos escândalos alimentares na mídia são aspectos que fazem com que os consumidores sintam mais fortemente a impossibilidade de ser e estar bem informado, resultando em um déficit de conhecimento.

Entre os consumidores de alimentos orgânicos de Nova Friburgo (RJ), Castañeda de Araujo (2010) assinala que apenas uma pequena 
parcela se considera plenamente informada para efetuar as melhores escolhas alimentares: a maioria deixa clara a necessidade de buscar incessantemente por mais informações, quando não assumem uma desinformação parcial.

A politização do campo da alimentação parece ir além de um processo seletivo de escolha por um alimento específico em uma miríade de possibilidades. A questão sobre qual item deve ser politizado por si só se tornou um instrumento político em função dos dilemas e das ambiguidades envolvidos nas escolhas cotidianas dos consumidores.

Nerlich (2004) entende que a escolha dos riscos que mais preocupam está associada a formas sociais específicas, pois são simultâneas às escolhas dos estilos de vida. ${ }^{13} \mathrm{O}$ risco não é construído apenas de uma forma científica, social e cultural, mas envolve uma questão individual cada vez mais importante, bem como, ultimamente, uma questão de moralidade que se materializa nas escolhas dos consumidores. Com isso, as reflexões cotidianas passaram a incluir aspectos como a globalização, a responsabilidade individual, o julgamento científico e as pressões socioeconômicas. Os riscos, que, à primeira vista, pareciam somente uma tragédia humana e animal passaram a abrir janelas de oportunidades políticas no campo da alimentação.

${ }^{13}$ De referência a Mary Douglas, ao analisar os discursos sobre as causas da febre aftosa na esfera pública inglesa, Nerlich (2004) observou razões de ordem cultural, histórica e semântica interagindo com as incertezas científicas. A autora configurou os seguintes pares opostos em que a "comida barata" aparece como "ruim" e a "comida cara" como "boa": inseguro e seguro, contaminado e descontaminado, natural e artificial, saudável e doentio, devagar e rápido, orgânico e processado, local e global, incomum e comum. cípio, são parte de um discurso transcultural estão, de fato, fortemente inseridas em valores e distinções extremamente específicas e localizadas. Na era da alimentação globalizada, as fronteiras entre os contextos locais e globais apresentam-se cada vez mais borradas. Dessa maneira, a alimentação constitui um fenômeno político único, pois o alimento é mais profundamente absorvido por complexas relações do que qualquer outro produto. Lien (2004) atribui três sentidos políticos ao campo da alimentação.

Primeiramente, há as implicações biológicas da alimentação: o alimento faz parte do corpo humano devido à necessidade humana fisiológica de se alimentar diariamente. Historicamente, os sistemas agroalimentares foram desenvolvidos para assegurar o suprimento estável de alimentos de diversas formas: domesticação, exploração, reciprocidade e comércio. Essa relativa estabilidade tornou os seres humanos vulneráveis, fracos e fáceis de controlar, o que torna o campo da alimentação parte de estruturas de subordinação, governabilidade e dominação.

Em segundo lugar, a alimentação caracteriza uma rotina cotidiana, um meio conveniente de expressar distinções sociais e cerimoniais que naturaliza relações comunitárias ou hierárquicas. O significado simbólico da comida em um contexto social pode ser visto como sedimentação de estruturas históricas de poder e desigualdade que operam ao longo de gerações. A alimentação se torna uma força estrutural e estruturante.

Em terceiro lugar, o campo da alimentação passa a ser entendido como "ciência nutricional" a partir do momento em que a nutrição se tornou um dos mais significativos campos da medicina preventiva e um agente estruturante das escolhas alimentares contemporâneas. No entanto, a nutrição científica contraria, ao mesmo tempo, os interesses agrícolas, bem como os da indústria alimentar, da comida nacional e das políticas nutricionais. Com isso, as conexões entre o alimento e o corpo evidenciam conflitos entre diferentes interesses: políticos, de negócios e da ciência.

Assim, uma abordagem política do cam- 
po da alimentação passa ao largo das instituições estatais formais, especialmente pela crise de legitimidade que as atinge, em geral, bem como pela desregulamentação e liberalização que afetam o campo da alimentação, em particular. A contestação das relações de poder existentes pode assumir diversas formas, muitas vezes pelos caminhos menos óbvios, como os da vida cotidiana.

Lien (2004) aponta a necessidade de atentar para as políticas da natureza englobadas discursivamente pelo termo ambientalismo, na medida em que não há uma natureza única e singular, mas uma diversidade de naturezas contestadas e constituídas através de vários processos políticos, sociais e culturais. Assim, quando um alimento é visto como mais ou menos "natural", produzido de um modo mais ou menos "sustentável" ou harmoniosamente adaptado a certas noções de natureza, o que se tem, de fato, é a inserção dos debates em um campo onde o que prevalece é a dúvida.

\section{NEXOS DE FAZERES E DISCURSOS DAS PRÁTICAS DE COMPRA DE ALIMENTOS ORGÂNICOS}

Ao realizar entrevistas em profundidade, Castañeda de Araujo (2010) entende a percepção dos consumidores sobre a relação entre a compra de alimentos orgânicos, o meio ambiente e a vida no campo. Com isso, nesta sessão, enfatizo as percepções desses consumidores sobre a responsabilidade frente aos problemas ambientais, as dificuldades e dilemas que encontram para desempenhar suas práticas de compra, bem como se e de que forma participam em prol de melhorias sociais e ambientais.

A relação entre a compra de alimentos orgânicos e o meio ambiente aparece como uma forma de os consumidores incentivarem a produção de alimentos em uma cadeia sustentável, com práticas agrícolas ecológicas, que não agridem o ambiente. A produção orgânica aparece como capaz, até mesmo, de recuperar os solos e os lençóis freáticos, que não são contaminados, sendo assim preservados, além de desmatar menos que a agricultura convencional. Assim, trata-se de atores sociais para os quais suas compras representam uma forma de contribuírem, intencionalmente ou não, para a preservação do meio ambiente e, portanto, para a melhoria do planeta em que vivem.

Com isso, o aumento da demanda por alimentos orgânicos é visto como um fator que pode acelerar a transição da atual hegemonia da produção convencional, com utilização de agrotóxicos e desmatamento de florestas, para outra, por eles considerada ideal: a produção orgânica. Esses consumidores entendem que suas compras de alimentos orgânicos constituem uma contribuição para a "melhoria do planeta". As referências feitas à integração entre os seres humanos e a natureza demonstram que esse entendimento deriva de uma ideia de respeito aos limites da natureza no processo de produção orgânica, visando ao equilíbrio ambiental e à produção de um alimento de qualidade.

Por outro lado, a relação entre a compra de orgânicos e a vida no campo não é tão evidente. Uma parcela considerável dos consumidores acredita que a produção orgânica é ética, porque oferece mais saúde ao homem do campo. Essa percepção se relaciona com o fato de os produtores não precisarem lidar com os agrotóxicos, além de se tratar de um processo produtivo que precisa de mais mão de obra e ser "ecologicamente correto". Assim, uma parcela significativa acredita que um aumento do consumo de alimentos orgânicos pode ter como consequência tanto a diminuição da migração do campo para a cidade quanto uma maior geração de renda para as zonas rurais.

No entanto, alguns consumidores apontam dificuldades para conceber essa relação como positiva, pois percebem que a produção orgânica parece ser mais interessante para eles do que para os homens do campo. Além disso, existem aqueles que não acreditam na força dessa relação, porque consideram que a maioria das pessoas que produz 
esses alimentos não depende dessa atividade para viver, ou aferem grandes lucros, de forma a caracterizar apenas mais um negócio.

Os aspectos destacados até aqui refletem uma percepção das práticas de compra de alimentos orgânicos como um processo de comoditização das relações de produção. ${ }^{14}$ Entretanto, para além de uma relação de produção com menor impacto ambiental ou mesmo da preocupação com os produtores rurais, alguns consumidores enxergam que suas práticas de compra de alimentos orgânicos refletem sintomas de mudanças mais amplas. Isso fica mais evidente nas seções seguintes, em que abordo aspectos relacionados com a autoatribuição de responsabilidades, bem como as formas de ação política usadas por esses atores sociais.

\section{Autoatribuição de responsabilidades}

Através das práticas de compra de alimentos orgânicos, alguns consumidores parecem se identificar como atores importantes no processo de mudança social e ambiental. Eles se autoatribuem responsabilidades e deveres (Eden, 1993; Portilho, 2008) e, assim, o ato de comprar "se transformou num meio de conferir objetividade a certos valores” (Miller, 2002, p.79).

Uma complexa transição de comportamentos relacionados com a responsabilidade socioambiental parece estar em curso. Eden (1993) mostra como uma responsabilidade percebida parece dar lugar a uma autoatribuição de responsabilidades pelos indivíduos, ativistas ou não. A responsabilidade socioambiental passa a depender cada vez mais da autoidentificação de indivíduos que se percebem como agentes social e ambientalmente úteis ou eficazes, agindo de acordo com um comportamento utilitário. ${ }^{15}$

${ }^{14}$ Barbosa e Campbell (2006, p.25) destacam que "as relacões de produção por trás de uma mercadoria são partes integrantes daquilo que é oferecido no mercado, em um processo de 'comoditização' e consumo crescente das relações de produção". Sobre comoditização das relações de produção, ver também Cochoy (2004) e Wilkinson (2006).

${ }^{15}$ Éden (1993) entende que isso constitui um problema para

a promoção da ideia de responsabilidade socioambiental
O processo de ambientalização e politização do consumo e da vida cotidiana se desenvolve na medida em que as escolhas diárias, e não só a compra, passam a envolver materializações cotidianas de valores políticos, morais e ecológicos. Essas escolhas constituem um dos principais meios para o exercício concreto da solidariedade e da ética da responsabilidade, sendo por meio delas que os indivíduos se sentem diretamente responsáveis por melhorar o meio ambiente e a vida de outras pessoas.

Esta autoatribuição de responsabilidades socioambientais pode significar um aumento da autoridade dos consumidores sobre a vida cotidiana, já que buscam se apropriar de conhecimentos, habilidades e competências perdidas para os especialistas (Eden, 1993). Ao perceber o significado e as consequências de suas ações no meio ambiente e em outros grupos sociais, os nexos de fazeres e discursos das práticas de compra podem representar um aumento dos sentimentos de cidadania e pertencimento a uma comunidade imaginária, o que ajuda a tornar essas práticas mais úteis e significativas (Portilho, 2008).

Em sua pesquisa, realizada no início dos anos 1990, Eden (1993) identificou que o reconhecimento pelo público se mostrava implícito e fracamente articulado, apesar do uso explícito da responsabilidade socioambiental por parte do governo, das empresas e organizações não governamentais. Nesse caso, os indivíduos ingleses reconheciam o que era socialmente definido como comportamento social e ambientalmente aceitável, mas não pareciam estar preparados para racionalizar os motivos pelos quais eram a favor do meio ambiente.

No entanto, a autoatribuição de responsabilidade frente aos problemas socioambientais aparece de forma explícita entre os consumidores de alimentos orgânicos em Nova Friburgo (RJ) (Castañeda de Araujo, 2010). Para eles, essa responsabilidade é de todos nós, ou seja, das pesso-

na medida em que os promotores desta ideia apelam ao público por meio dos mais altos valores morais, que seriam enfraquecidos se forem reorientados no sentido da utilidade. 
as de um modo geral, remetendo a algo inerente à esfera individual, de cada um dos seres humanos.

Apesar dessa evidência, os consumidores de alimentos orgânicos entrevistados em Nova Friburgo (RJ) associam uma parcela importante de responsabilidade pelos problemas ambientais àqueles que detêm o poder, em especial os empresários, bem como governos e legisladores, colocados no poder pelo povo. Alguns deles ainda evidenciam o sistema capitalista como um modelo problemático, que reúne consumismo, gasto energético e busca do lucro, com grande responsabilidade por essa problemática. Apenas uma pequena parcela desses consumidores se encaixa nos extremos possíveis: a existência de vários níveis de responsabilidade na questão dos problemas ambientais, ou uma autoatribuição de responsabilidades total, por meio de uma atitude restrita de fazer a sua parte por meio de escolhas de consumo ambientalmente corretas.

Os consumidores entrevistados consideram seu desempenho em práticas de compra de alimentos orgânicos como um elemento importante para a resolução dos problemas ambientais contemporâneos. Alguns deles condicionam a importância desse desempenho a um nexo de preservação ambiental, enquanto outros enfatizam a informação como componente fundamental para uma postura mais consciente e o exercício da pressão.

Castañeda de Araujo (2010) assinala a relação entre a informação que os consumidores em geral possuem e a consciência necessária para desempenhar práticas de compra de alimentos orgânicos como aspecto importante. A fraqueza dessa relação aparece como uma restrição para que mais pessoas comprem esses alimentos. Os consumidores apontam a necessidade de o público em geral obter mais informações para assumir responsabilidades frente aos problemas ambientais a partir de suas práticas de compra.

Entratanto, alguns consumidores optam por reagir através de um consumo que consideram o mais correto possível, na medida em que percebem que a preocupação com a própria saú- de, ao adotar a alimentação orgânica, se relaciona intrinsecamente com as melhorias no meio ambiente. O aumento da oferta aparece como principal entrave para aumentar a demanda por alimentos orgânicos, o que, para eles, constitui o principal fator de pressão para imprimir mudanças no mercado agroalimentar.

Os consumidores de alimentos orgânicos se sentem social e ambientalmente responsáveis em suas práticas, mas apontam dificuldades em exercer essa responsabilidade em todos os momentos da vida cotidiana. Eles evidenciam forte autocrítica e certa culpabilização (Eden, 1993), pois acreditam que deixam a desejar em algumas escolhas, com especial destaque para a utilização de sacolas plásticas, uma prática que é declaradamente importante para muitos deles, mas que, na maioria das vezes, é deixada de lado. Dessa forma, a autoatribuição de responsabilidades identificada nos nexos de fazeres e discursos das práticas de compra de alimentos orgânicos em Nova Friburgo (RJ) constitui um aspecto importante para a emergência de novas formas de ação política frente aos problemas ambientais na esfera da vida cotidiana e no consumo. Nesse sentido, a seguir, caracterizo as formas de ação política que tais nexos configuram.

\section{Formas de ação política}

A politização do consumo compreende "escolhas de consumo de produtores e produtos com base em considerações políticas ou éticas" (Stolle et al, 2005, p.246). Nesse sentido, certos consumidores politizados escolhem determinados produtos e produtores na medida em que buscam mudanças institucionais ou, de forma cada vez mais intensa, das práticas de mercado.

De forma individual ou coletiva, as escolhas desses atores sociais mostram que eles percebem os produtos escolhidos em um contexto normativo de uma complexidade social. Com isso, o declínio de grupos políticos tradicionais parece ser compensado por um relativo aumen- 
to de importância de organizações informais, de ações individualizadas e de redes de mobilização. Stolle et al. (2005) destacam, como exemplos desse aumento de importância: a participação em grupos locais informais, a politização do consumo, as assinaturas regulares em petições on line e a organização espontânea, por vezes individualizada, de protestos.

Nesse sentido, um aspecto que merece destaque, inicialmente, são as dificuldades que os consumidores entrevistados encontram para ter acesso aos alimentos orgânicos. Ao contrário do que possa parecer, em função dos altos preços característicos desses produtos, remetendo à ideia de estarem sempre disponíveis para compra, os consumidores tinham de superar obstáculos para adquiri-los em Nova Friburgo (RJ), tais como a baixa oferta e variedade de alimentos. A superação dessas dificuldades reforça a autoatribuição de responsabilidades desses consumidores frente aos problemas socioambientais, conformando, assim, sintomas de um movimento de politização em uma esfera mais individualizada (Alexander, 1995; Beck, 2002).

Entre os consumidores de alimentos orgânicos em Nova Friburgo (RJ), Castañeda de Araujo (2010) entende que as práticas cotidianas constituem uma das principais formas de manifestação política em relação aos problemas socioambientais. Esse aspecto traduz os processos de ambientalização e politização da vida cotidiana (Portilho, 2005) refletidos na racionalização do uso doméstico de bens e serviços, como água, energia, automóvel, separação de resíduos e utilização de sacolas ecológicas, entre outros (Portilho; Castañeda, 2009).

No que se refere ao engajamento e à militância em ONGs ambientalistas, predominam os consumidores que não estavam engajados nessas instituições. ${ }^{16}$ Eles destacam a ausência de vínculos

${ }^{16}$ Considerando os quinze entrevistados, três deles disseram fazer parte de ONGs ambientalistas. Desses, apenas um exercia função de direção na Fundação Natureza, uma disse ser colaboradora da Officina Escola Mãos de Luz e o outro se encontrava licenciado da União das Árvores, porque exercia uma função pública gratificada. Os doze consumidores de alimentos orgânicos restantes que entrevistei não faziam parte de qualquer organização diretamente relacionada com institucionais, especialmente quando dizem que não efetuam doações ou mesmo que deixaram de doar dinheiro para ONGs. Para além do engajamento em uma organização institucionalizada, os entrevistados relatam uma participação ativa em benefício do meio ambiente. Entre as novas formas de ação política, Castañeda de Araujo (2010) assinala que os abaixo-assinados virtuais surgem como importantes frentes de ação política desses consumidores.

Cabe aqui destacar a percepção das práticas de compra de alimentos orgânicos em Nova Friburgo (RJ) como buycott. Mesmo que nenhum consumidor desses alimentos tenha identificado suas práticas de compra com esse termo, Castañeda de Araujo (2010) conclui que tais práticas constituem uma inovadora forma de ação política na esfera do consumo, frente à crise ambiental. Para grande parte dos consumidores, a compra de alimentos orgânicos materializa uma opção preferencial por um alimento que vai de encontro à hegemonia dos padrões produtivos do sistema agroalimentar global.

Em Nova Friburgo (RJ), o buycott parece ser reforçado em função de um contexto adverso para a compra de alimentos orgânicos. Os consumidores apontam várias dificuldades para desempenhar essas práticas, tais como preços elevados, baixa oferta e pouca variedade de produtos no mercado, bem como pouca e contraditória informação sobre a alimentação orgânica. Essas práticas materializam um caráter político e de resistência e compõem uma obstinada preocupação desses consumidores, tanto com a própria saúde, quanto com a saúde do planeta, aspectos que aparecem relacionados nos nexos apreendidos.

Os boicotes também são colocados em prática, mesmo que por uma parcela menor dos entrevistados, sendo que alguns destacam a esfera do ciberespaço, mais particularmente da

as questões ambientais. Cabe ressaltar que uma entrevistada era presidente da Associação Macaé de Cima, outra fazia parte do Rotary Club e uma terceira disse estar filiada ao Partido dos Trabalhadores (PT). Da mesma forma, um dos entrevistados fazia parte do Grupo de Agricultura Orgânica de Nova Friburgo, parte do movimento de agricultores orgânicos no estado do Rio de Janeiro. 
rede de relacionamentos Orkut, assim como a frente contra os transgênicos e a rede de fast food McDonald's.

A presente análise não pretende sugerir que as ações coletivas tendem a desaparecer, como se nota nos discursos de alguns deles. Porém Castañeda de Araujo (2010) entende que uma transição do padrão de ações políticas do tipo radical-coletivistas para aquelas românticoindividualistas (Alexander, 1995) parece se materializar entre os consumidores de alimentos orgânicos que observei em Nova Friburgo (RJ).

\section{CONCLUSÕES}

A análise dos nexos de fazeres e discursos das práticas de compra de alimentos orgânicos em Nova Friburgo (RJ) indica valores e propósitos de participação política e autoatribuição de responsabilidades socioambientais entre os consumidores pesquisados. Essa autoatribuição de responsabilidades é constantemente negociada, constituindo um elemento fundamental na configuração de novas formas de ação política frente aos problemas ambientais. Trata-se de ações individualizadas, desenvolvidas na esfera do consumo, como o buycott, e da vida cotidiana, como a racionalização do uso de bens e serviços.

Considerando o contexto de uma sociedade de risco global (Beck, 2002) e o imaginário dos consumidores, os alimentos orgânicos representam uma relação de produção sustentável, saudável, solidária, ética e responsável, entre outras características. Por meio das práticas de compra desses alimentos, os consumidores acreditam contribuir para evitar os riscos da produção escondida e misteriosa das indústrias agroalimentares, ou mesmo dos alimentos produzidos pela agricultura intensiva convencional, com base na utilização de pesticidas e agrotóxicos.

Os processos de ambientalização e politização do consumo e da vida cotidiana se materializam nas práticas de compra de alimentos orgânicos, pois, por meio da compra, os con- sumidores buscam incentivar relações de produção que proporcionem um impacto reduzido no meio ambiente, caracterizando um processo de comodotização da produção orgânica. Além disso, essa opção preferencial de compra de um alimento (buycott) tem sua faceta de politização reforçada em função da reflexividade social sobre os riscos alimentares contemporâneos à saúde humana.

Todo um contexto adverso para o desempenho das práticas de compra de alimentos orgânicos em Nova Friburgo (RJ) tem seu contraponto na persistência e obstinação dos consumidores no sentido de superar tais obstáculos. As dificuldades encontradas aparecem como mais um sinal de politização dessas práticas, na medida em que não basta que os consumidores tenham condições financeiras para praticar a compra: eles precisam desenvolver táticas específicas para comprar esses produtos.

Portanto, uma autoatribuição de responsabilidades frente aos problemas socioambientais é evidente entre os consumidores de alimentos orgânicos pesquisados em Nova Friburgo (RJ). Os nexos analisados mostram que a responsabilidade é de todos nós, ou seja, algo que deveria ser inerente a cada um dos seres humanos que vivem no planeta. Isso faz com que eles se sintam responsáveis pela preservação ambiental ao praticar o buycott, por meio da compra de alimentos orgânicos, ou racionalizar o uso cotidiano de bens e serviços.

Entretanto, esses agentes entendem que uma parcela significativa, e talvez até maior, dessa responsabilidade é daqueles que "detêm o poder", compreendendo um conjunto que envolve as empresas transnacionais, cadeias de lojas, empresários, governos e até, como não poderia faltar, o sistema capitalista. Além disso, mostramse culpados, revelando uma forte autocrítica e culpabilização quando verificam que não conseguem ser tão responsáveis quanto gostariam.

Os consumidores não incorporam totalmente as responsabilidades socioambientais que os governos, as ONGs, as empresas, a opinião 
pública e a mídia, de uma forma geral, lhes imputam. Eles negociam essas responsabilidades e se consideram, em grande parte, corresponsáveis. Ao destacar que podem "fazer a sua parte", mas não irão resolver os problemas socioambientais sozinhos, eles demonstram um misto de posturas preocupadas e pragmáticas (Halkier, 2004).

A importância que os consumidores conferem ao acesso à informação, como instrumento de uma tomada de consciência que eles consideram necessária para desempenhar práticas de compra de alimentos orgânicos, reforça a saída que Portilho (2005) vislumbra para a "crise ambiental". Apesar de reconhecer a importância das ações individualizadas cotidianas nos processos de ambientalização e politização do consumo e da vida cotidiana, a eficácia global desses processos depende de um transbordamento comunicativo entre as microesferas cotidianas, capaz de construir uma esfera pública globalizada que transcenda o tradicional e, cada vez mais, ineficiente diálogo transnacional e interinstitucional, incorporando novos atores e redes não institucionalizadas.

Por fim, cabe destacar que a ação política dos consumidores frente aos problemas socioambientais contemporâneos mescla ações inovadoras e tradicionais de posicionamento político (Castañeda de Araujo, 2010).

Entre as ações inovadoras, de cunho mais co por meio da assinatura de abaixo-assinados on line posiciona a internet como proeminente esfera de participação ativa em benefício do meio ambiente e da solidariedade nas sociedades contemporâneas. Os boicotes foram citados menos intensamente, apontando para o fato de que é uma forma de protesto pouco usada nas mobilizações brasileiras na esfera do consumo. Ainda assim, os consumidores destacaram alguns boicotes contra redes de fast food, empresas multinacionais e produtos que usam sementes transgênicas.

A atuação em instituições como ONGs, associações, governos, clubes de serviço e partidos políticos também pode ser encontrada por meio das entrevistas, porém em uma pequena parcela dos consumidores de alimentos orgânicos pesquisados em Nova Friburgo (RJ). Dessa forma, Castañeda de Araujo (2010) aponta para uma transição dos padrões de ação política dos movimentos radicais-coletivistas para ações romântico-individualistas, caracterizando um período neomoderno (Alexander, 1995).

No entanto, a análise das práticas de compra de alimentos orgânicos em Nova Friburgo (RJ), como parte integrante dos processos de ambientalização e politização do consumo e da vida cotidiana, também aponta para o estabelecimento de pontes entre consumo e cidadania (Canclini, 1995). Com isso, um novo período de engajamento público coletivo (Hirschman, 1983) pode ser iniciado, desde que as microesferas cotidianas se comuniquem, provocando a emergência de novas ações comunicativas em uma dinâmica e renovada esfera pública global (Portilho, 2005).

(Recebido para publicação em 23 de setembro de 2011) (Aceito em 14 de março de 2012)

\section{REFERÊNCIAS}

ALEXANDER, Jeffrey. Modern, ante, post, and neo: how intellectuals have coded, narreted, and explained the "crisis of our times". In: ALEXANDER, Jeffrey. Fin-de-siècle social theory: relativism, reduction, and the problem of reason. Londres: Verso, 1995. 
BARBOSA, Lívia. Tendências da alimentação contemporânea. In: PINTO, Michelle de Lavra; PACHECO, Janie K. Juventude, consumo \& educação. Porto Alegre: ESPM, 2009.

CAMPBELL, Colin. O estudo do consumo nas ciências sociais contemporâneas. In: Cultura, consumo e identidade. Rio de Janeiro: Editora FGV 2006.

BARDIN, Laurence. Análise de conteúdo. Lisboa: Edições $70,1977$.

BECK, Ülrich. A reinvenção da política: rumo a uma teoria da modernização reflexiva. In: GIDDENS, Anthony. et al. Modernização reflexiva: política, tradição e estética na ordem social moderna. São Paulo: Universidade Estadual Paulista, 1997. p.11-71.

La sociedad del risco global. Madrid: Sieglo XXI de Espana Editores, 2002.

CANCLINI, Nestor Garcia. Consumidores y ciudadanos conflictos multiculturales de la globalización. México: Editorial Grijalbo, 1995.

CANESQUI, Ana Maria; GARCIA, Rosa Wanda Diez. Introdução. In: ; Antropologia e nutrição: um diálogo possível. Rio de Janeiro: Editora FIOCRUZ, 2005.

CASTAÑEDA DE ARAUJO, M. Ambientalização e politização do consumo e da vida cotidiana: uma etnografia das práticas de compra de alimentos orgânicos em Nova Friburgo/RJ. 2010. Dissertação (Mestrado) - CPDA/ Universidade Federal do Rio de Janeiro, 2010.

EDEN, S. E. Individual environmental responsability and its role in public environmentalism. Environmental and Planning, [S.l.], v.25, n.12, p.1743-1758, 1993.

GIDDENS, Anthony. As conseqüências da modernidade. São Paulo: UNESP, 1991.

Para além da esquerda e da direita: o futuro da política radical. São Paulo: UNESP, 1996.

A vida em uma sociedade pós-tradicional. In et al. Modernização reflexivel: politica, tradição e estética na ordem social moderna. São Paulo: Universidade Estadual Paulista, 1997.
HALKIER, Bente. Handling food-related risks: Political Agency and Governamentality. In: LIEN, Marianne Elisabeth; NERLICH, Brigitte. Politics of food. Oxford, New York: Oberg, 2004.

HIRSCHMAN, Albert. De consumidor a cidadão: atividades privadas e participação na vida pública. São Paulo, Brasiliense, 1983.

LIEN, Marianne Elisabeth. The politics of food: An introduction. In: food. Oxford: New York: Oberg, 2004.

MILLER, Daniel. Teoria das compras. O que orienta as escolhas dos consumidores. São Paulo: Nobel, 2002.

NERLICH, Brigitte. Risk, Blame and Culture: foot and mouth disease and the debate about cheap food. In: LIEN, Marianne Elisabeth; NERLICH, Brigitte. Politics of food. Oxford, New York: Oberg, 2004.

PAAVOLA, J. Economics, ethics and Green consumerism. In: COHEN, M. e MURPHY, J. (eds). Exploring sustainable consumption: environmental policy and the social sciences. Oxford: Elsevier Science, 2001, pp. 79-96.

PORTILHO, Fátima. Sustentabilidade ambiental, consumo e cidadania. São Paulo: Cortez, 2005.

Consumidores de alimentos orgânicos: discursos, práticas e auto-atribuição de responsabilidade socioambiental. In: REUNIÃO BRASILEIRA DE ANTROPOLOGIA, 26, 2008, Porto Seguro (BA), Anais... São Paulo: ABA, 2008.

Sociabilidade, confiança e consumo na feira de produtos orgânicos. In: BARBOSA, Lívia; PORTILHO, Fátima; VELOSO, Letícia. Consumo: cosmologias e sociabilidades. Rio de Janeiro: Mauad X; Seropédica: EDUR, 2009.

; CASTAÑEDA, Marcelo. Consumo e Política: Neo-modernismo e reflexividade social. In: CONGRESSO BRASILEIRO DE SOCIOLOGIA, 16, 2009, Rio de Janeiro. Anais... São Paulo: 2009.

STOLLE, Dietlind; HOOGHE, Marc; MICHELETTI, Michele. Politics in the supermarket: political consumerism as a form of political participation. International Politica Science Review, Paris, IPSA, v.26, n.3, p.245-269, 2005.

WARDE, Alan. Consumption and theories of practice. Journal of Consumer Culture. [S.l.], Sage, v.5, n.2, p.13153, jul. 2005 


\section{ENVIROMENTALIZATION AND POLITICIZATION OF CONSUMPTION IN ORGANIC FOOD PURCHASING PRACTICES}

\author{
Marcelo Castañeda
}

This article's main objective is to reflect upon the processes of environmentalization and politicization of consumption in daily life, emphasizing the multisided field of alimentation. The text focuses on different forms of organic food purchasing practices, by considering the consumers as social actors. The main research questions are the following: Are the organic food purchasing practices perceived as a form of political action? How do consumers deal with the environmental discourse and the demand of responsibility regarding the environmental crisis? Through an ethnographic study of the organic food purchasing practices, the article reveals an increasing individual autonomy concerning political choices in the field of consumption, when public and private spheres meet. Organic food purchasing is perceived as part of a repertoire of individualistic romantic political actions, building bridges to citizenship and creating possibilities for new collective actions.

KEY-WORDS: environmentalization and politicization of consumption, daily life, purchasing practices, organic food.

\section{SENSIBILISATION À L'ENVIRONNEMENT ET POLITISATION DE LA CONSOMMATION POUR LACHAT DES PRODUITS BIOS}

\author{
Marcelo Castañeda
}

L'objectif visé est de réfléchir aux processus de sensibilisation à l'environnement et de politisation de la consommation dans la vie quotidienne, en mettant l'accent sur les diverses facettes de l'alimentation. L'article traite des différentes habitudes concernantl'achat des aliments biologiques et considère les consommateurs comme des acteurs sociaux. Leproblèmecentral tourneautour desquestions suivantes:Lachat de produitsalimentaires biologiques est-il perçu commeuneattitude politique? De quelle manière les consommateurs réagissentils aux discours et aux appels à la responsabilité envers la crise environnementale? Sur la base d'une etnographie des comportements d'achat d'aliments bios et d'interviews approfondies, l'article identifie une croissance de l'autonomie politique individuelle par rapport aux sphères publiques et privées dans le domaine de la consommation. L'achat de produits biologiques est considéré comme un répertoire de l'action politique romantique individuelle. Ces pratiques ouvrent la voie à la citoyenneté et offrent la possibilité d'un engagement collectif.

Mots-CLÉs: sensibilisation à l'environnement et politisation de la consommation, quotidien, pratiques d'achats, alimentation biologique.

Marcelo Castañeda - Doutorando em Ciências Sociais em Desenvolvimento, Agricultura e Sociedade pela Universidade Federal Rural do Rio de Janeiro - CPDA/UFRRJ, com mestrado concluído na mesma instituição. Possui graduação em Ciências Sociais pela Universidade do Estado do Rio de Janeiro. Tem experiência nas áreas de Metodologia e Epistemologia, Antropologia e Sociologia, com ênfase em ação política, tecnologia e consumo. Trabalhos realizados ou em andamento: ação coletiva, internet, novas tecnologias da informação, meio ambiente, alimentação, cultura material, estilos de vida, desigualdades, direitos humanos e violência. Em 2010, recebeu o Prêmio Associação Nacional de Pós-Graduação e Pesquisa em Ambiente e Sociedade (ANPPAS) de melhor dissertação de mestrado, com o título "Ambientalização e politização do consumo e da vida cotidiana: uma etnografia das práticas de compra de alimentos orgânicos em Nova Friburgo/RJ”. 